\title{
Kajian Probabilitas Jatuhnya Pesawat Terbang Di Area Tapak Reaktor Daya Eksperimental (RDE) PUSPIPTEK Serpong
}

\author{
Yarianto Sugeng B.S*, Siti Alimah, June Mellawati \\ Pusat Kajian Sistem Energi Nuklir (PKSEN) - BATAN,Jalan Kuningan Barat, Mampang Prapatan Jakarta 12710,
}

\begin{tabular}{l}
\hline INFORMASI ARTIKEL \\
\hline Riwayat Artikel: \\
Diterima: \\
1 Februari 2017 \\
Diterima dalam bentuk revisi: \\
13 Februari 2017 \\
Disetujui: \\
20 Februari 2017 \\
\end{tabular}

Kata kunci:

Probabilitas jatuhnya

pesawat,

SDV,

KKOP,

RDE.

\begin{abstract}
ABSTRAK
KAJIAN PROBABILITAS JATUHNYA PESAWAT TERBANG DI AREA TAPAK REAKTOR DAYA EKSPERIMENTAL (RDE) DI KAWASAN PUSPIPTEK SERPONG. Telah dilakukan kajian probabilitas jatuhnya pesawat terbang di area tapak RDE di kawasan Puspiptek Serpong untuk keperluan perizinan tapak RDE. Tujuan penelitian untuk mengetahui probabilitas kejadian jatuhnya pesawat terbang di area tapak RDE. Metodologi penelitian yang digunakan meliputi pengumpulan data sekunder dan primer, identifikasi sumber potensi bahaya (bandara) di sekitar tapak RDE dan pemetaan sebarannya, penapisan awal menggunakan nilai Screening Distance Value (SDV) dan Kawasan Keselamatan Operasi Penerbangan (KKOP), serta perhitungan nilai probabilitas jatuhnya pesawat di area tapak. Penelitian dilakukan bulan Desember 2015 - Juni 2016. Hasil penelitian menunjukkan di sekitar tapak RDE terdapat 7 lapangan terbang, yaitu Soekarno Hatta (Soetta), Halim Perdanakusuma, Atang Sendjaja, Budiarto, Pondok Cabe, Rumpin dan Pulau Panjang dengan jarak berkisar 11,72 - 79,641 km dari tapak RDE. Berdasarkan nilai SDV (bandara kecil $10 \mathrm{~km}$ \& besar $16 \mathrm{~km}$ ) tapak RDE berada di luar radius SDV bandara. Namun demikian, berdasarkan KKOP $(14,5 \mathrm{~km})$, tapak RDE berada dalam radius KKOP dari 2 bandara yaitu Budiarto dan Pondok Cabe. Perhitungan probabilitas menunjukkan bahwa potensi jatuhnya pesawat terbang di area tapak RDE yang berasal dari Bandara Budiarto $0,0066 \times 10^{-7}$ kejadian/tahun dan dari Pondok Cabe $0,0278 \times 10^{-7}$ kejadian/tahun. Nilai probabilitas tersebut masih lebih rendah dibandingkan kriteria dalam laporan IAEA $\left(10^{-7}\right.$ kejadian/tahun) sehingga tapak RDE dikategorikan aman dari potensi jatuhnya pesawat terbang.

ABSTRACT

STUDY ON THE PROBABILITY OF THE AIRCRAFT CRASH AT THE EXPERIMENTAL POWER REACTOR (RDE) SITE IN PUSPIPTEK SERPONG. With regard to RDE site licensing process, probability of aircraft crash at RDE site area of Puspiptek Serpong has been assessed The objective of the research (assessment) is to determine the probability of occurrence of aircraft crash at the RDE site area. The methodology used in the research consist of secondary and primary data collection, identification of potential hazards sources (airports) in the vicinity of RDE site and mapping of its distribution, initial screening using a value of Screening Distance Value (SDV) and Safety Region of Flight Operations value (KKOP), as well as the calculation of the probability of the aircraft crash in the site area. The study was conducted in December 2015 - June 2016. The results showed that in the vicinity of the RDE site there are seven airports airport, namely Soekarno-Hatta (Soetta), Halim Perdanakusuma, Atang Sendjaja, Budiarto, Pondok Cabe, Rumpin and Pulau Panjang, with distances ranging from 11.72 to $79.64 \mathrm{~km}$. Based on the SDV (small airport is $10 \mathrm{~km}$ and a large airport is $16 \mathrm{~km}$ ), the RDE site is in outside of the airports SDV radius. However, based on KKOP (14.5 km radius), the RDE site is in inside of the two airports KKOP radius (Budiarto and Pondok Cabe). Probability calculations showed that the potential of aircraft crash in the site area of RDE coming from the Budiarto airports is $0,0066 \times 10^{-7}$ events/year and from Pondok Cabe $0,0278 \times 10^{-7}$ events/year. The probability value was lower than the criteria based on IAEA report ( $10^{-7}$ events/year), so the RDE site categorized safe from the potential of aircraft crash.

Keywords: Probability of aircraft crash, SDV, KKOP, RDE
\end{abstract}

(c) 2016 Jurnal Pengembangan Energi Nuklir. All rights reserved

\section{PENDAHULUAN}

Berbagai kejadian eksternal akibat ulah manusia (external human induced events) yang berada di sekitar tapak, salah satunya yaitu keberadaan bandara dan koridornya

*Penulis korespondensi.

E-mail: yarianto@batan.go.id berpotensi memberikan ancaman terhadap instalasi nuklir (PLTN) sehingga perlu mendapat perhatian dan hal tersebut telah dikaji sebelumnya[1,2]. Kajian terhadap probabilitas kecelakaan pesawat terbang di Indonesia pada jalur penerbangan komersial 
domestik juga telah dilakukan dan diperoleh nilai $5,4 \times 10^{-9}$ kecelakaan per pesawat/km[3]. Hal ini juga banyak dijelaskan dalam dokumen IAEA Safety Standards Series NS-R-3 (2003) tentang Site Evaluation for Nuclear Installations yang salah satunya adalah kecelakaan pesawat terbang[4]. Mengingat kejadian eksternal akibat ulah manusia jenis ini (pengoperasian pesawat terbang) dapat menyebabkan bahaya kebakaran dan ledakan sehingga perlu dihitung potensi bahayanya[5]. Dokumen IAEA Safety Standards Series No. NS-G-3.1 (2002) tentang "External Human Induced Events in Site Evaluation for Nuclear Power Plants" menyatakan bahwa jalur penerbangan udara (zona bandara/penerbangan) sipil maupun militer dikategorikan sebagai sumber bergerak dan merupakan sumber eksternal akibat ulah manusia yang harus dipertimbangkan dalam proses evaluasi tapak PLTN. Dokumen IAEA Safety Guides No. NS-G-1.2 (2001) tentang Safety Assessment and Verification for Nuclear Power Plant menjelaskan bahwa kecelakaan pesawat terbang merupakan salah satu kejadian eksternal akibat ulah manusia di sekitar tapak PLTN sehingga perlu untuk dikaji[6]. IAEA Safety Guides No. 50-SG-S5 (1981) Guidance External Man-Induced Events In Relation To Nuclear Power Plant Sitting menyatakan bahwa kecelakaan pesawat terbang merupakan sumber yang berpotensi membahayakan instalasi nuklir karena dapat menyebabkan kejadian kebakaran, ledakan tanki bahan bakar, sehingga perlu diidentifikasi dan dipertimbangkan jarak keberadaannya terhadap instalasi nuklir (PLTN) [7].

Berdasarkan hal tersebut BAPETEN telah memberikan panduan dalam penentuan tapak PLTN di Indonesia terkait kejadian eksternal jatuhnya pesawat terbang, yaitu Perka BAPETEN No. 5 tahun 2007 tentang Pedoman Ketentuan Keselamatan Evaluasi Tapak Reaktor Nuklir, dan Perka BAPETEN No. 6 Tahun 2008 untuk Aspek Kejadian Eksternal Akibat Ulah Manusia[8,9]. Zona bandara/penerbangan (militer dan sipil) dan koridor lalu lintas udara termasuk salah satu sumber bergerak yang berpotensi membahayakan instalasi nuklir sehingga keberadaan dan kegiatannya perlu diidentifikasi dan dihitung nilai probabilistik bahayanya. Perka BAPETEN No. 01-P/KaBAPETEN/VI-99 menjabarkan berbagai faktor yang salah satunya adalah keadaan karakteristik lingkungan, yaitu lapangan terbang/bandara yang menurut ketentuan pemerintah harus dijaga keutuhan dan keamanannya[10].

Jatuhnya pesawat terbang di area KKOP (sekitar tapak) dapat menimbulkan kejadian eksternal akibat bahaya ledakan dan kebakaran yang memicu terlepasnya bahan beracun dan materi radioaktif dari instalasi nuklir. Berdasarkan pertimbangan tersebut perlu dilakukan kajian probabilitas jatuhnya pesawat terbang di area tapak RDE mengingat walaupun tapak RDE berada di luar SDV bandara, namun masih berada dalam radius KKOP 2 bandara. Tujuan penelitian adalah untuk mengetahui potensi jatuhnya pesawat terbang di area tapak RDE di Kawasan Puspiptek Serpong, berdasar nilai SDV lapangan terbang/bandara, KKOP dan faktorfaktor yang mempengaruhi jatuhnya pesawat ke area tapak dengan cara menghitung probabilitasnya.

\section{TEORI}

\subsection{Pengertian Sumber Bergerak, Bandara dan Koridor Udara, serta KKOP}

Sumber bergerak merupakan sumber dengan lokasi pemicu kecelakaan tidak menetap (bergerak), misalnya zona bandara/penerbangan (militer maupun sipil) dan koridor lalu lintas udara[5,6]. Bandara adalah daerah tertentu di daratan (termasuk bangunan, instalasi dan peralatan) yang digunakan baik seluruhnya maupun sebagian bagi kedatangan, keberangkatan dan pergerakan pesawat udara di darat. Koridor udara adalah wilayah udara khusus dimana sebuah pesawat harus tetap terbang/ berada di jalur terbang tersebut selama melintasi daerah tersebut.

Koridor udara dapat menjadi bantuan navigasi bagi pilot untuk boleh keluar jalur ketika kondisi tidak memungkinkan, namun tetap terbang/berada di koridor udara khusus. KKOP (Kawasan Keselamatan Operasi Penerbangan), menurut UU No.1 tahun 2009 adalah tanah dan/atau perairan dan ruang 
udara di sekitar bandar udara yang dipergunakan untuk kegiatan operasi penerbangan dalam rangka menjamin keselamatan dan keamanan penerbangan, serta melindungi masyarakat di sekitar bandar wilayah dimana pesawat tidak diizinkan untuk terbang di area tertentu. Dalam istilah kemiliteran disebut zona demiliterisasi di udara. Zona ini melarang pesawat militer sebuah bangsa yang sedang berperang

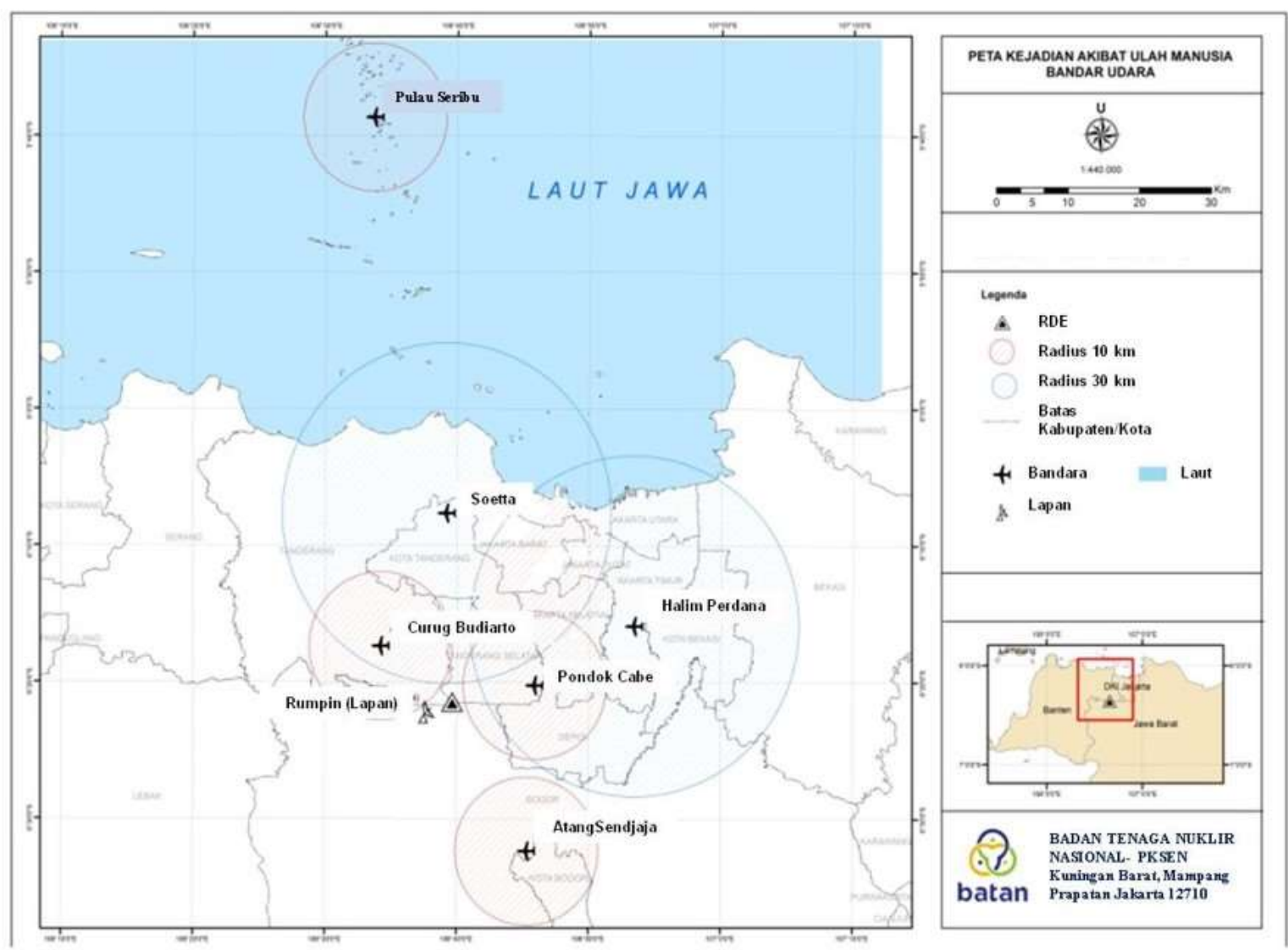

Gambar 1. Peta Sebaran Bandara/Lapangan Terbang di Sekitar Tapak RDE[14].

udara terhadap kemungkinan bahaya kecelakaan pesawat udara[11]. Dalam penerbangannya, pesawat mengikuti koridor atau lorong-lorong penerbangan selebar \pm $14,5 \mathrm{~km}$ (nilai KKOP) yang dipisahkan oleh perbedaan ketinggian vertikal 1.000-2.000 feet $( \pm 300-600 \mathrm{~m})$. Nilai KKOP tidak perlu dipertimbangkan (terhadap potensi bahaya jatuhnya pesawat) apabila tapak berada di luar radius $\mathrm{KKOP}$.

\subsection{Pengertian Zona Penerbangan dan Nilai SDV}

Zona Penerbangan (Militer \& Sipil) adalah suatu daerah penerbangan yang diperbolehkan dilalui oleh pesawat udara dari negara manapun setelah mendapatkan ijin terbang. Zona larangan terbang adalah sebuah melakukan penerbangan di zona yang ditetapkan sebagai zona larangan terbang.

Kriteria Screening Distance Value (SDV) adalah kriteria berdasarkan nilai jarak penapisan, yaitu jarak antara sumber bahaya potensial suatu kejadian eksternal yang dalam hal ini adalah bandara/lapangan terbang/lanud terhadap tapak fasilitas nuklir (PLTN). Dalam dokumen IAEA Safety Series NS-G-3.1, SDV untuk bandara tidak disebutkan secara eksplisit, namun penentuan SDV tersebut dilakukan melalui pendekatan dan sepenuhnya diserahkan kepada negara-negara anggota IAEA termasuk Indonesia[5]. Menurut IAEA, SDV (jarak bandara ke tapak) untuk bandara dengan pesawat-pesawat kecil adalah $10 \mathrm{~km}$ dan bandara besar (internasional) adalah 16 $\mathrm{km}$. Keberadaan bandara tersebut tidak perlu dipertimbangkan potensi bahayanya jika tapak 
berada di luar SDV. Namun dalam kasus ini, tapak RDE berada di dalam radius KKOP bandara Pondok Cabe dan Budiarto, karena jarak masing-masing bandara ke tapak adalah 11,72 dan 12,55 km. Oleh karena itu berdasar penerbangan; A adalah area tapak yang efektif (mil persegi); W adalah lebar jalur penerbangan (ditambah 2 kali jarak ke tapak, bila tapak berada di luar jalur penerbangan), dalam mil.
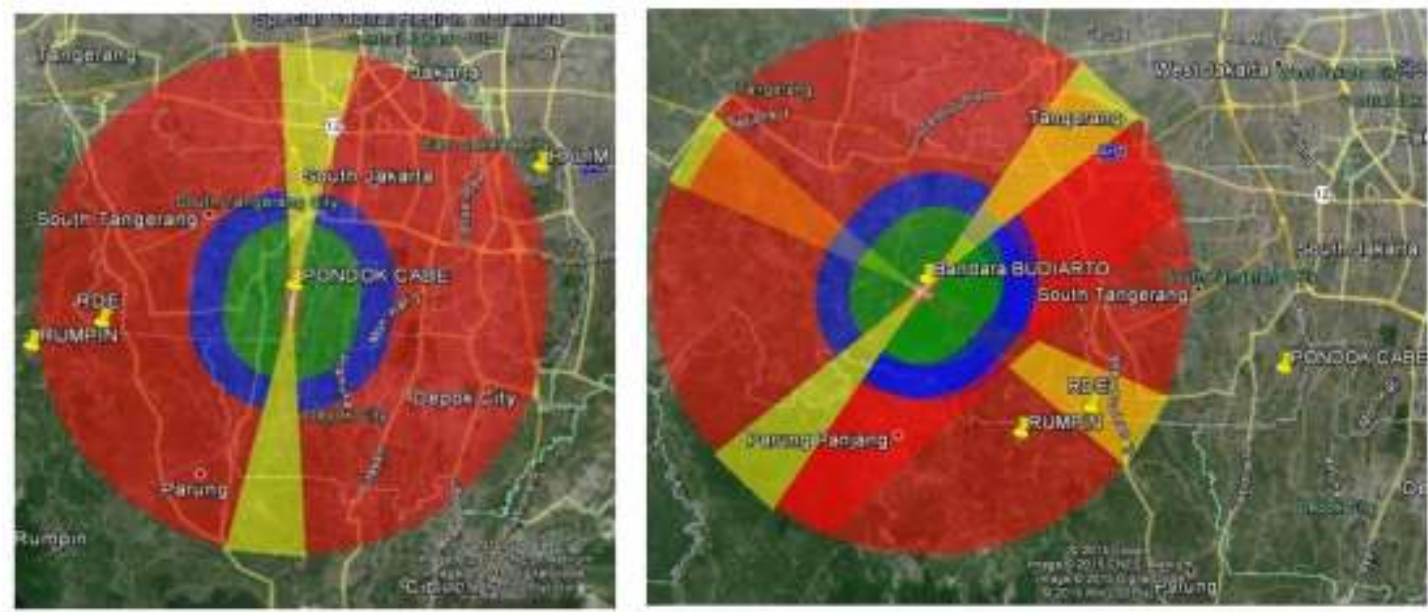

Gambar 2. Tapak RDE Berada di Dalam Radius KKOP Bandara Pondok Cabe dan Budiarto[14]

Keterangan :

Warna Kuning: kawasan pendekatan dan lepas landas

Warna Hijau: kawasan berputar di atas bandara menunggu kesempatan mendarat

Warna Biru: kawasan yang melindungi pergerakan pesawat khusus dalam posisi manuver untuk melakukan pendekatan Warna Merah: kawasan yang melindungi pergerakan pesawat dalam posisi kegagalan pendaratan akibat kondisi cuaca uruk (UU No 1/2009, Ps. 206 tentang Penerbangan).

UU No. 1 tahun 2009, khusus untuk bandara Pondok Cabe dan Budiarto perlu dihitung probabilistik bahaya jatuhnya pesawat terbang di area tapak RDE (kejadian/tahun)[11].

\subsection{Probabilistik Jatuhnya Pesawat Terbang}

Berdasarkan pendekatan frekuensi relatif, bahwa nilai probabilitas/peluang ditentukan atas dasar proporsi dari kemungkinan yang dapat terjadi dalam suatu observasi/percobaan (pengumpulan data). Menurut US NRC (2004) dan LEE, dkk., (1993), nilai probabilitas jatuhnya pesawat terbang di sekitar tapak PLTN dapat dihitung menggunakan rumus berikut[12,13].

$$
\mathrm{P}_{\mathrm{FA}}=\mathrm{CxNx}_{\mathrm{N}} \frac{\mathrm{A}}{\mathrm{W}}
$$

dimana: C adalah laju kecelakaan penerbangan per mil untuk pesawat yang menggunakan jalur penerbangan; $\mathrm{N}$ adalah jumlah pergerakan pesawat per tahun di sepanjang jalur

\section{METODOLOGI}

Kegiatan penelitian meliputi pengumpulan data sekunder (karakteristik bandara, jenis pesawat, lebar jalur penerbangan, data jumlah pergerakan pesawat /tahun, dll.) dan primer (pengukuran jarak bandara-tapak RDE, titik koordinat bandara, dll.), identifikasi sumber potensi bahaya (bandara/ lapangan terbang/ lanud) hingga radius $25 \mathrm{~km}$ dari tapak $\mathrm{RDE}$, pemetaan sebaran bandara di sekitar tapak dan penapisan awal menggunakan nilai SDV dan KKOP. Evaluasi tapak untuk aspek kejadian akibat ulah manusia khusus sumber bergerak pesawat terbang dilakukan pada radius $25 \mathrm{~km}$ dari tapak[14]. Selanjutnya dilakukan perhitungan nilai probabilitas jatuhnya pesawat di area tapak, berdasar persamaan 1 . Penelitian dilakukan pada bulan Desember tahun 2015 s/d Juni tahun 2016. Data sekunder diperoleh dari instansi pemerintah maupun narasumber di lokasi penelitian. 


\section{HASIL DAN PEMBAHASAN}

\subsection{Identifikasi Sumber Potensi Bahaya (Bandara) di Sekitar Tapak RDE}

Di sekitar tapak RDE terdapat sebanyak 7 buah lapangan terbang/bandara/lanud, yaitu: (a) Bandara Soekarno Hatta (Soetta), (b) Halim Perdanakusuma, (c) Budiarto, (d) Pondok Cabe, (e) Lanud Atang Sendjaja, (f) Lapangan Terbang Rumpin dan (g) Pulau Panjang.

Bandara Soetta merupakan bandara lokal (domestik) dan internasional yang digunakan untuk penerbangan sipil dan bukan pangkalan militer, berlokasi di Tangerang. Bandara Halim Perdanakusuma merupakan bandara lokal (domestik) dan internasional, militer, pendidikan penerbangan kepresidenan, yang dikelola oleh PT. Angkasa Pura II, berada di Kecamatan Kramatjati, Jakarta timur. Bandara Budiarto merupakan bandara sipil nonkomersial sebagai tempat latihan calon pilot dan saat ini digunakan oleh Sekolah Tinggi Penerbangan Indonesia (STPI) yang terletak di Kecamatan Curug, Kabupaten Tangerang. Bandara Pondok Cabe terletak di Desa Pondok Cabe Udik, Kecamatan Pamulang, Kota Tangerang Selatan, dimiliki oleh PT. Pertamina dan merupakan home base untuk Pelita Air Service (anak perusahaan Pertamina). Selain untuk penerbangan sipil juga digunakan sebagai pangkalan militer, antara lain pangkalan dari Skuadron 21/Sena. Dinas Penerbangan Angkatan Darat (Dispenerbad) dan Dinas Polisi Air dan Udara (Polairud). Bandara Atang Sendjaja merupakan Pangkalan TNI-AU yang sebelumnya bernama Pangkalan Udara Semplak. Bandara ini terletak di Kelurahan Semplak, Kecamatan Bogor Barat, Kota Bogor. Lapangan Terbang Rumpin merupakan lapangan terbang bekas peninggalan Jepang dan tidak aktif digunakan sebagai bandara, berlokasi di Desa Sukamulya, Kecamatan Rumpin, Kabupaten Bogor. Lapangan terbang Pulau Panjang terletak di Pulau Panjang, Kelurahan Pulau Kelapa, Kecamatan Kepulauan Seribu Utara Kabupaten Kepulauan Seribu, DKI Jakarta. Kondisi lapangan terbang ini tidak terawat dan memerlukan perbaikan dan reklamasi untuk pengembangannya.

\subsection{Pemetaan Bandara yang Ada di Sekitar Tapak RDE dan Penapisan Awal Menggunakan Nilai Jarak Penapisan (Screening Distance Value/SDV)}

Hasil pemetaan bandara yang ada di sekitar tapak RDE ditunjukkan pada Gambar 1. Data hasil penapisan awal menggunakan SDV beberapa bandara yang ada di sekitar lokasi tapak RDE ditunjukkan pada Tabel 1.

Tabel 1. Data Beberapa Bandara yang Ada di Sekitar Lokasi Tapak RDE [14]

\begin{tabular}{llccc}
\hline & Nama Bandara & Jenis Bandara & Nilai SDV & Jarak ke tapak RDE (km) \\
\hline 1 & - Soekarno Hatta & Besar & $16 \mathrm{~km}$ & 25,48 \\
2 & - Halim Perdanakusuma & Besar & $16 \mathrm{~km}$ & 27,41 \\
3 & - Pondok Cabe & Kecil & $10 \mathrm{~km}$ & 11,72 \\
4 & - Atang Sendjaja & Kecil & $10 \mathrm{~km}$ & 22,67 \\
5 & - Budiarto & Kecil & $10 \mathrm{~km}$ & 12,55 \\
6 & - Rumpin & Kecil & $10 \mathrm{~km}$ & 5,15 \\
7 & - Pulau Panjang & Kecil & $10 \mathrm{~km}$ & 79,64 \\
\hline
\end{tabular}

Berdasarkan peta sebaran bandara (Gambar 1) dan data penapisan (Tabel 1) menggunakan SDV, diketahui bahwa tapak RDE berada di luar SDV bandara-bandara tersebut, hal ini terlihat bahwa jarak tapak RDE terhadap bandara > nilai SDVnya. Oleh karena itu tidak berpeluang memberikan kejadian eksternal terhadap instalasi RDE, seperti yang diatur dalam Perka BAPETEN dan Dokumen IAEA. Terkecuali lapangan terbang Rumpin tidak dikaji lebih lanjut dan diabaikan mengingat lapangan terbang tersebut merupakan peninggalan Jepang yang sudah tidak diaktifkan lagi. Namun demikian perlu diketahui bahwa terdapat regulasi lainnya, yaitu Undang Undang No.1 Tahun 2009 yang menyatakan bahwa radius KKOP adalah 14,5 km[11]. Artinya tapak RDE berada 
di dalam radius KKOP Bandara Budiarto dan Pondok Cabe, seperti yang diatur dalam regulasi penerbangan di Indonesia[15,16]. Hasil pemetaan tapak RDE berada di dalam radius KKOP Bandara Pondok Cabe dan Budiarto ditunjukkan pada Gambar 2.

\subsection{Probabilitas Jatuhnya Pesawat}

Probabilitas jatuhnya pesawat terbang yang berasal dari Bandara Budiarto dan Pondok Cabe, dihitung menggunakan datadata seperti ditunjukkan Tabel 2. Nilai probabilitas jatuhnya pesawat $\left(\mathrm{P}_{\mathrm{FA}}\right)$ yang dilaporkan negara-negara di dunia (IAEA, 2002) sebesar $10^{-7}$ kejadian/tahun [3,17]. Hasil perhitungan diperoleh probabilitas jatuhnya pesawat dari Bandara Pondok Cabe $\left(\mathrm{P}_{\mathrm{FA}}\right)$ di kawasan tapak RDE adalah 0,0278 $\times 10^{-7}$ kejadian/tahun, sedangkan dari bandara Budiarto $\quad 0,0066 \quad \times 10^{-7} \quad$ kejadian/tahun. Perhitungan dengan asumsi semua pesawat bebas bergerak, baik di koridor maupun di lintasan sama. Hasil perhitungan berdasar persamaan 1:

Untuk Bandara Pondok Cabe :

$$
\begin{aligned}
\mathrm{PA} & =\left(4 \times 10^{-10}\right) \times 5110 \times 0,0199 / 14,5929 \\
& =0,0278 \times 10^{-7} \text { (kejadian/tahun) }
\end{aligned}
$$

Untuk Bandara Budiarto :

$$
\begin{aligned}
\mathrm{PA} & =\left(4 \times 10^{-10}\right) \times 1300 \times 0,0199 / 15,6250 \\
& =0,0066 \times 10^{-7} \text { (kejadian/tahun) }
\end{aligned}
$$

\begin{tabular}{|c|c|c|}
\hline \multirow[t]{2}{*}{ Parameter } & \multicolumn{2}{|c|}{ Bandara: } \\
\hline & PondokCabe & Budiarto \\
\hline Jarak bandara ke tapak RDE. Jarak dari & $11,72 \mathrm{~km}$ & $12,55 \mathrm{~km}$ \\
\hline $60 \mathrm{~m})[18]$ & $11,12 \mathrm{~km}(6,18 \mathrm{mil})$ & $11,95 \mathrm{~km}(6,64 \mathrm{mil})$ \\
\hline $\begin{array}{l}\text { C (Laju kecelakaan penerbangan per mil } \\
\text { untuk pesawat yang menggunakan jalur } \\
\text { penerbangan)[12] }\end{array}$ & \multicolumn{2}{|c|}{$4 \times 10^{-10}$} \\
\hline $\begin{array}{l}\text { N (Jumlah pergerakan pesawat per tahun } \\
\text { di sepanjang jalur penerbangan) [18] }\end{array}$ & $\begin{array}{l}14 \text { penerbangan/hari } \\
\text { (5110/tahun) }\end{array}$ & $\begin{array}{l}5 \text { penerbangan/hari } \\
\text { (1300/tahun) }\end{array}$ \\
\hline $\begin{array}{l}\text { A (area tapak (RDE) efektif (dalam mil } \\
\text { persegi) yang dilalui pesawat)[19] }\end{array}$ & \multicolumn{2}{|c|}{$5,16 \mathrm{Ha}\left(51.634 \mathrm{~m}^{2}\right.$ atau $\left.0,019936 \mathrm{mil}^{2}\right)$} \\
\hline $\begin{array}{l}\text { W (lebar jalur (ditambah } 2 \text { kali jarak ke } \\
\text { tapak, jika tapak di luar jalur penerbangan) } \\
\text { dalam mil }\end{array}$ & $\begin{array}{c}14,5929 \text { mil atau } \\
{[45 \mathrm{~m}+(2 \times 11,72 \mathrm{~km})]}\end{array}$ & $\begin{array}{c}15,625 \text { mil atau } \\
{[46 \mathrm{~m}+(2 \times 12,55 \mathrm{~km})]}\end{array}$ \\
\hline
\end{tabular}

Tabel 2. Data Karakteristik Bandara Pondok Cabe dan Budiarto Untuk Menghitung Nilai Probabilitas (SPL) Jatuhnya

Hasil perhitungan tersebut menunjukkan bahwa apabila Bandara Pondok Cabe jika di kemudian hari dijadikan bandara komersial, maka peluang terjadinya kecelakaan jatuhnya pesawat terbang ke area tapak RDE sangat kecil dan tidak berpeluang membahayakan.

Demikian pula peluang terjadinya kecelakaan jatuhnya pesawat terbang yang berasal dari Bandara Budiarto ke area tapak RDE juga sangat kecil dibandingkan yang dilaporkan IAEA, $2002\left(10^{-7}\right.$ kejadian/tahun) sehingga tapak RDE termasuk kategori aman[5].

\section{KESIMPULAN}

Di sekitar tapak RDE ditemukan sebanyak 7 buah lapangan terbang/bandara/ 72 lanud, yaitu Bandara Soekarno Hatta (Soetta), Halim Perdanakusuma, Budiarto, Pondok Cabe, Lanud Atang Sendjaja, Rumpin, dan Pulau Panjang. Berdasarkan penapisan awal menggunakan SDV diketahui bahwa tapak RDE berada di luar SDV ke tujuh lapangan terbang tersebut karena jarak tapak RDE cukup jauh dan tidak berpotensi memberikan bahaya terhadap instalasi RDE. Namun demikian tapak RDE berada di dalam radius KKOP kedua bandara, yaitu Pondok Cabe dan Budiarto sehingga perlu diperoleh gambaran peluang bahaya jatuhnya pesawat ke area tapak RDE. Probabilitas jatuhnya pesawat terbang dari kedua bandara tersebut ke area tapak RDE di Kawasan Puspiptek Serpong relatif kecil, yaitu $0,0066 \times 10^{-7}$ (kejadian/tahun) untuk Bandara Budiarto dan 0,0278 × $10^{-7}$ (kejadian/tahun) untuk Bandara Pondok Cabe, dan nilai 
probabilitas ini lebih kecil dibandingkan yang dilaporkan IAEA sehingga tapak RDE termasuk kategori aman dari kejadian jatuhnya pesawat terbang.

\section{UCAPAN TERIMAKASIH}

Penulis mengucapkan terimakasih kepada Ir. Sriyana, MT, selaku Kepala Bidang KDT PKSEN BATAN yang telah memberikan pengarahan terhadap kegiatan penelitian ini hingga penyusunan laporan, dan teman-teman yang telah membantu pengumpulan data. Penulis juga mengucapkan terimakasih kepada Bapak Abas dan Ibu Nur dari STIP Curug Budiarto yang telah membantu dalam pengumpulan data.

\section{DAFTAR ACUAN}

[1]. J. Mellawati, Y. S. Budi Susilo, H. Suntoko. "Sumber Potensial Bahaya Eksternal Akibat Kegiatan Manusia Pada Survei Tapak PLTN”. Jurnal Pengembangan Energi Nuklir. Vol. 12, No. 1, Juni 2010, Hal. 28-37.

[2]. J. Mellawati, Fepriadi, dan Y. S. Budi Susilo, "Identifikasi Sumber Kejadian Akibat Kegiatan Manusia Pada Pra-Survei Tapak PLTN Di Pulau Bangka”. Prosiding Seminar Nasional Pengembangan Energi Nuklir IV, Jakarta, 2011, Hal 49-61.

[3]. N. S. Syam. "Kajian Awal Frekuensi Jatuhnya Pesawat Terbang Pada Tapak PLTN Dari Jalur Penerbangan". Prosiding Seminar Keselamatan Nuklir. Jakarta. 2011. Hal. 392-400.

[4]. Site Evaluation for Nuclear Installations, IAEA Safety Standards Series, Safety Requirement No. NS-R-3, 2003.

[5]. External Human Induced Events in Site Evaluation for Nuclear Power Plants. IAEA Safety Standard Series, No. NS-G-3.1, 2002.
[6]. Safety Assessment and Verification for Nuclear Power Plants. IAEA Safety Guides, No. NS-G-1.2, 2001.

[7]. Guidance External Man-Induced Events In Relation To Nuclear Power Plant Sitting. No. 050-SG-S5. 1981.

[8]. Peraturan Kepala Badan Pengawas Tenaga Nuklir No. 5 tahun 2007 tentang Pedoman Ketentuan Keselamatan Evaluasi Tapak Reaktor Nuklir. Jakarta. 2007.

[9]. Peraturan Kepala Badan Pengawas Tenaga Nuklir No. 6 tahun 2008 tentang Evaluasi Tapak Reaktor Daya Untuk Aspek Kejadian Eksternal Akibat Ulah Manusia. Jakarta. 2008.

[10]. Keputusan Kepala Badan Pengawas Tenaga Nuklir No. 01-P/Ka-BAPETEN/VI-99 tentang Pedoman Penentuan Tapak Reaktor Nuklir. Jakarta. 2007

[11]. Undang Undang Republik Indonesia No. 1 Tahun 2009 tentang Penerbangan. Jakarta. 2009.

[12]. Aircraft Hazards. U.S. NRC Standard Review Plan. NUREG-0800. Rev. 2. July 1981.

[13]. L.G. Lee, J.M. Mines, B.B. Webb. “Assessment of Aircraft Impact Possibilities at The Idaho Chemical Processing Plant on The Inel Site". Westinghouse Idaho Nuclear Company, Inc. U.S. Department of Energy Idaho Operations Office. August 1993.

[14]. Badan Tenaga Nuklir Nasional. "Laporan Evaluasi Tapak RDE Aspek KAUM”. Revisi 2. 2016.

[15]. Peraturan Menteri Perhubungan. No. KM 34 Tahun 2007. Tentang Kawasan Keselamatan Operasi Penerbangan di Sekitar Bandar Udara Budiarto, Curug Menhub RI. Jakarta. 2007.

[16]. Peraturan Menteri Perhubungan No. KM 32 Tahun 2007 tentang Kawasan Keselamatan Operasi Penerbangan di Sekitar Bandar Udara Pondok Cabe Tangerang. Jakarta. 2007.

[17]. H. Choi. "Geography, Demography and HumanInduced Hazards". Asian Nuclear Safety Network, June 2012

[18]. ARI. Komunikasi Pribadi, STPI, Budiarto Curug. Juli 2016

[19]. RENUKO. "Preparation of Preliminary Engineering Design Document for Experimental Power Reactor (RDE)". Final Report Feasibility Study Site Development Plan. Appendix 3 Site Development Plan. Jakarta. December 2015. 